\title{
Rethinking scientific responsibility
}

\author{
Annika Forssén, ${ }^{1}$ Eivind Meland, ${ }^{2}$ Irene Hetlevik, ${ }^{3}$ Roger Strand ${ }^{4}$
}

${ }^{1}$ Department of Public Health and Clinical Medicine, Division of Family Medicine, Umeå University, and Department of Research and Development, Norrbotten County Council, Luleå, Sweden

${ }^{2}$ Department of Public Health and Primary Health Care, University of Bergen, Bergen, Norway

${ }^{3}$ Research Unit for General Practice, Department of Public Health and General Practice, Norwegian University of Science and Technology (NTNU),

Trondheim, Norway

${ }^{4}$ Centre for the Study of the Sciences and the Humanities, University of Bergen, Bergen, Norway

\section{Correspondence to}

Professor Annika Forssén, Department of Research and Development, Norrbotten County Council, 97189 Luleå, Sweden; annika.forssen@nll.se

Received 2 July 2010 Revised 26 November 2010 Accepted 10 December 2010 Published Online First 25 January 2011

\section{(2) UNLOCKAD}

This paper is freely available online under the BMJ Journals unlocked scheme, see http:// jme.bmj.com/site/about/ unlocked.xhtml

\section{ABSTRACT}

Researchers should be made co-responsible for the wider consequences of their research focus and the application of their findings. This paper describes a meta-reflection procedure that can be used as a tool to enhance scientific responsibility and reflective practice. The point of departure is that scientific practice is situated in power relations, has direction and, consequently, power implications. The contextual preconditions and implications of research should be stated and discussed openly. The reflection method aims at revealing both upstream elements, such as for instance preconceptions, and downstream elements, for example, public consequences of research. The validity of research might improve from such discussions. Validity should preferably be understood as a broader concept than the methodological concerns in science.

As general practitioners (GPs) (AF, EM, IH) and researchers, we are active participants in medical development, leading us to reflect on the scientific knowledge needed and produced. Many GPs are also concerned about sustainable and responsible medicine, particularly in the light of the increased research focus on risks and the escalating demands for medical prevention. ${ }^{1}{ }^{2}$ However, the medical scientific community seems to regard itself as largely detached from society, merely supplying users with disinterested information. ${ }^{34}$ Within the scholarly fields studying the relationships between science, technology and society, this dissociative view of value-neutral science and value-laden use was rejected on empirical and theoretical grounds decades ago. ${ }^{5}$ The acknowledgement that scientific practice is value-laden, uncertain, open-ended and embedded in complex contexts urges for a rethinking of scientific responsibility. ${ }^{6}$ In this paper we present a method of reflection centred around the concept 'situated knowledges', emphasising that scientific knowledge depends on where and by whom it is created. The method is in exploratory use by the authors and their colleagues.

\section{INCREASING MEDICAL DILEMMAS}

Medical research promoting technological examinations and treatments increasingly influences general practice, creating and exacerbating conflicts that can be difficult to handle. Such technologies imply improved prognoses for some, but at the same time a growing number of risk diagnoses narrow the limits for normality, causing stress, dissatisfaction and ethical dilemmas in general practitioner's (GP) consultations. ${ }^{19} 10$ Guidelines, incentives and targets promoting higher biomedical standards may improve practice performance, but tend to undermine the traditional strength of general practice - the focus on dialogue and relationship building. ${ }^{11} 12$ Medicine seems to become more technologically competent, but may at the same time undervalue and dismiss the subjective experiences of health and health resources. ${ }^{13-15}$ Meanwhile, large numbers of people become ill with complex diseases, such as chronic fatigue or pain syndromes, which prevailing medical models fail to understand. ${ }^{4-17}$ Not only patients, but also doctors, may experience estrangement and health impairment. ${ }^{410} 18$

The conflicts outlined above have to be handled by individual GPs, who become responsible for interpreting science in a way that gives meaning and hope to the patient. ${ }^{11} 16$ Politicians are held responsible for the broader social and ethical assessment of medical science and the proper use of economic resources. ${ }^{4}$

While holding potential for improved practice, the development outlined above also carries inherent conflicts and dilemmas. Increased demands to diagnose, prevent and cure increase the costs. ${ }^{18}$ Other side-effects have been discussed, for example in terms of medicalisation, increased risk of harming and growing inequalities in health care. $^{131819}$ GPs, working at the crossroads between health care as a medical-technological and as a humanistic enterprise, are particularly exposed to conflicts arising from this development. ${ }^{1} 22021$

\section{SCIENCE HAS DIRECTION-AND CREATES REALITY}

A common metaphor for science is a cone of light illuminating an increasing part of a dark map. In this image of science-delineated and dismantled by Thomas Kuhn already in 1962-the scientist has no personal location, and is invisible, signifying objectivity and scientific freedom. ${ }^{5}$ Even if the scientist always is a person with a social, cultural and political identity, the scientific method is held to cleanse science of 'external' or 'non-epistemic' values. ${ }^{3}$ Thus, within this picture, scientific development is both neutral (in terms of its objectivity), good in itself (in terms of utility), and is expected to lead to continuous social progress (Figure 1). ${ }^{3} 5$ The most important consequence of this 'functional myth' is that the scientific community cannot be held responsible for what it simply 'uncovers'. 8 Therefore, the scientist has no moral responsibility other than that prescribed by norms of scientific honesty and methodology and traditional medical ethics such as embodied in the Declaration of Helsinki. We believe this concept still holds sway within the scientific community in spite of accumulating research showing the complex entanglements of economics, politics and culture with science. 346

Sponsors of research budgets have huge influence on what is investigated, ie, on the direction of 'the 
cone of light'. By funding academic research, the pharmaceutical industry has increased its impact on the design, evaluation and reporting of medical research. ${ }^{22}{ }^{23}$ Among the most frequently cited medical articles, the proportion funded by the industry has increased during the past few decades. ${ }^{22}$ The same industry influences what is considered a disease, and which risks and diseases should be subject to medical attention. ${ }^{23}$ There is also cultural influence. Most influential research has affiliation in developed countries, above all the USA. ${ }^{22}$ Research from the west is attributed international significance, whereas research from non-industrial countries tends to be seen as local and mainly illustrating the influence of culture. ${ }^{24}$ The thinker, Michel Foucault, introduced the concept 'power-knowledge', rendering any analysis inadequate that treated power and knowledge as separable phenomena. ${ }^{25}$

The biomedical model and idea of specific aetiology, together with a pressure on researchers to produce results that are readily applicable, favour simplified explanations, followed by drug therapy or other technologically based interventions. ${ }^{4}{ }^{26}$ Despite the inability of this model to meet challenges raised by modern research concerning causation, other directions are relatively neglected, leading to the production of 'more of the same knowledge' in many fields. ${ }^{4} 26$ This affects society's understanding of what is counted as a disease or as 'at-risk' status, and what is considered as cause, prevention and cure. It also affects people's perceptions of their own bodies and the world around them. ${ }^{1-49}$

Although mainstream medical science often presents itself as value free, on a larger scale European political institutions are beginning to question the detached view maintained by the scientific community, and ask for broader input under the label of governance of science. This applies particularly to 'front line sciences' such as biotechnology and the nanosciences. For example, the European Commission has produced a code of conduct for responsible nanosciences and nanotechnologies, in which the responsibility for sustainability, precaution and meaningfulness of research has been laid on the research community. $^{27}$

\section{SITUATED KNOWLEDGES-A USEFUL CONCEPT?}

The image of the scientist neutrally uncovering the secrets of nature was described as the 'God-trick' by the biologist and philosopher of science Donna Haraway, likening it to a gaze that 'sees everything from nowhere'. How then, can the selfunderstanding of science be informed? What new concepts could be used for this purpose? Haraway proposes the concept of 'situated knowledges' against that of 'objectivity'. 'Situated knowledges' elucidate the limits and partiality of scientific knowledge, arguing that knowledge must be interpreted in relation to the context in which it is created. At the same time, the concept recognises the strengths that knowledge created from a particular perspective may possess. When scientists declare and reflect on their 'situatedness', it allows different findings and other forms of knowledge to be considered, opening up more fundamental scientific and public debate. ${ }^{6-8}$

\section{METHOD FOR META-REFLECTION}

As knowledge is situated, the context should be exposed to structured exploration. A method designed for this purpose has been further developed during seminars organised by the Philosophical Polyclinic in Bergen, Norway (http://www.uib.no/isf/ filpol/). It also forms an integral part of the training component for $\mathrm{PhD}$ students at several faculties at the University of Bergen, as delivered by that university's Centre for the Study of the Sciences and Humanities. The method covers the entire research process, divided into three parts. The initiation, design and planning of a study are called 'upstream elements', and include prerequisites, assumptions and previous knowledge. The 'midstream elements' concern the execution of the study. The final part, concerning the potential consequences of the study-to individuals, health care and to society-is termed 'downstream elements'. The idea is to elicit elements in each part relevant to the ethical, social and political aspects of the research.

\section{Upstream elements}

Upstream elements include: Who funds the study, and why? Why was it initiated? Who designed it, and how does this influence the project? What understanding of illness, disease and prevention shapes the project? To what extent does this depend on available medical technology? What choices and thus, values, are inherent in the definitions of a disease and the assessments of risk, and how do they travel mid and downstream? Why is the research question posed right now? Topicality, political signals, strategic ventures of the research institution, funding possibilities, power and prestige inherent in the topic, the need to establish a new research area, or an existing database, may all be relevant.

\section{The study (midstream elements)}

Internal review boards and ethics committees are mainly concerned with the ethics of information and consent, as well as the immediate risk to research subjects. When eliciting the situatedness of the study execution, more questions need to be asked. These include broader ethical questions, such as the potential consequences of this approach for individuals, families, the healthcare system and society. It is also important to ask questions about situated and value-laden dimensions of the

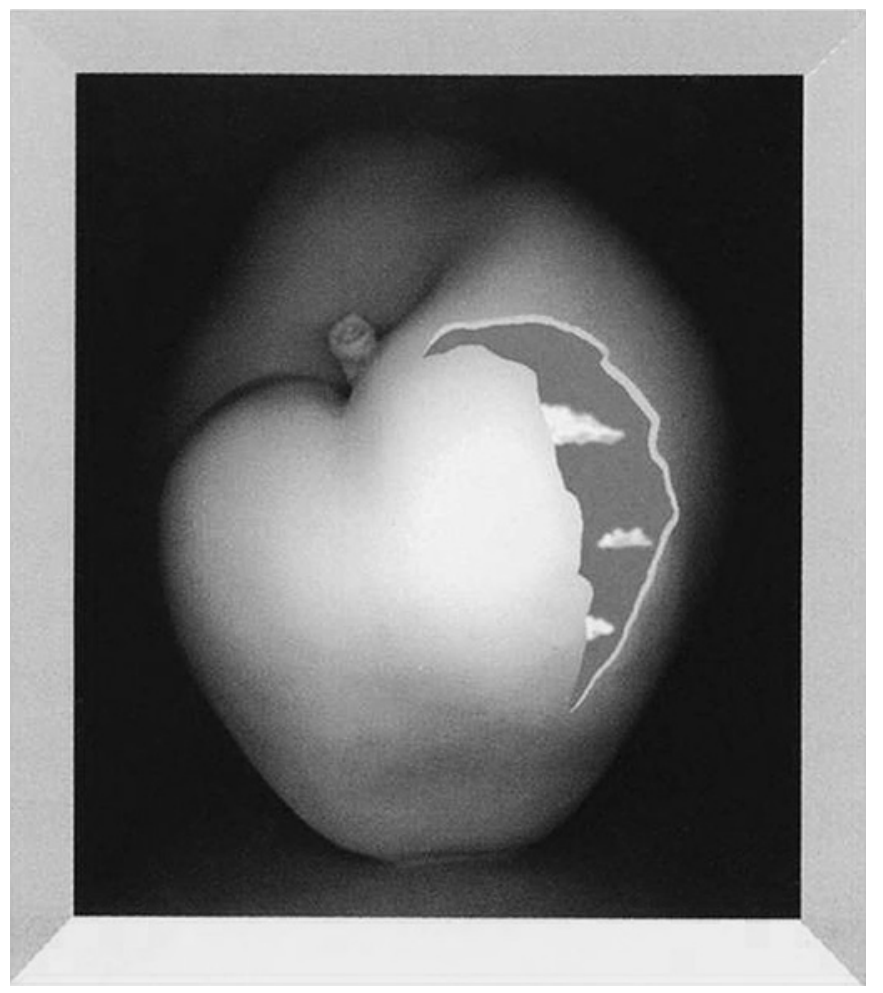

Figure 1 A functional myth of medical scientific development. Reproduced with permission of Marie Sterte. 
chosen methodology. This is partly a question of validity-for instance whether a natural science, phenomenological or hermeneutic, approach is most relevant to the research question. However, it goes beyond that, acknowledging that each choice of method in effect produces different knowledge and knowledge gaps. Therefore, in our exercise, we ask: after performing the study, what will not be known, which uncertainties will remain, be sidelined, or even produced?

\section{Downstream elements}

Publicly financed scientists are expected to publish and convey their findings without considering the consequences, while researchers financed by the pharmaceutical industry may have to adapt to the sponsoring companies' decisions regarding whether, when and in what form to publish the results. ${ }^{23}$ Popular reporting of scientific findings may have unforeseen consequences, such as the 'worried well', the questionable use of healthcare resources and professional dilemmas for the doctor. In the third phase of the exercise, potential downstream effects of a project are discussed, such as the possible consequencesbenefits, costs, risks and opportunities to the individual, to the healthcare system and to society. It should also be asked how the project might influence the general and medical understanding of the condition or disease, and where this may direct future focus regarding its prevention and treatment. Obviously, the answers will be speculative and highly uncertain, but still potentially important.

\section{Implementation}

The method may be tested out on an already published study. Two persons, the author and a moderator, are needed. Depending on available time, the audience reads the abstract or the entire paper. The author presents the main results, and time is allowed for clarification of uncertainties. Questions regarding the internal validity of the study may be posed. The researcher is then encouraged to reveal what he/she considers are the most important validity limitations. After discussion in small groups, the audience formulates what they regard to be the main finding(s) and the key message(s). The moderator asks for reformulations of such messages as punchline newspaper headings. Then the concepts of 'up-mid and downstream' elements are presented by the moderator and discussed in separate groups. Suggestions are noted on a white board. In the subsequent discussion, the audience is encouraged to identify up-mid and downstream elements and connections between them.

Finally, the responsible researcher reviews the elements that have been pointed out. For the exercise to work, the researcher should defend his/her work without resorting to weakness or withdrawal, but also avoid becoming defensive. The dialogue must be based on mutual respect. The objective is to contribute to greater understanding, not to political correctness.

This indeed follows from the perspective of 'situated knowledges'. Also the reflection contained in this paper, as well as the exploratory method we have presented, have their own valueladenness and situatedness - in our case that of the experience of the medical dilemmas described above (Box 1). The legitimacy of our approach, as much as any other, depends on the context, which is why we present it and hope for future reports of how it works in different settings.

The method becomes more important when planning or executing new research, because possible outcomes can be taken into consideration before the research is undertaken or written up. In such cases, the audience will be asked to formulate

\section{Box 1 Summary points}

The side-effects of medical research, such as increasing ethical dilemmas in medical practice, raising medical costs and a growing number of the worried well, deserve greater attention.

- We see these problems as linked to the view that scientific method cleanses science of 'external' or 'non-epistemic' values, that scientific knowledge is value-neutral and good in itself.

-We suggest the concept of 'situated knowledge' to inform the self-understanding of science.

- A method is presented for eliciting such situatedness and its consequences, leading to enhanced scientific responsibility.

possible future findings of the study. The model can be used regardless of whether the research is qualitative or quantitative.

\section{CONCLUSION}

We consider the method suitable for the academic training of faculty members and $\mathrm{PhD}$ candidates. In future, a summary of such a process might be added to the research report or paper, and if further taught and trained, could be required for publication in medical journals.

\section{Competing interests None.}

Contributors $A F, I H$ and $E M$ conceived the paper in close cooperation, following discussions in the Nordic Risk Group (http://www.nordicriskgroup.com). EM and RS have been the most involved in developing the method. RS contributed substantially during the draft revisions. AF has been the coordinator and main author, and is guarantor of the article. All gave final approval of the version submitted.

Provenance and peer review Not commissioned; externally peer reviewed.

\section{REFERENCES}

1. Getz L, Sigurdsson JA, Hetlevik I. Is opportunistic disease prevention in the consultation ethically justifiable? BMJ 2003;327:498-500.

2. Gérvas J, Heath I, Durán A, et al; Members of the Seminar of Primary Health Innovation 2008 (Seminario de Innovación en Atención Primaria 2008). Clinical prevention: patients' fear and the doctor's guilt. Eur J Gen Pract 2009;15:122-4.

3. Whitt LA. Value-bifurcation in bioscience: the rhetoric of research justification. Perspective on Science 1999;7:413-46.

4. Pauli HG, White KL, McWhinney IR. Medical education, research, and scientific thinking in the 21 st century (part one of three). Educ Health (Abingdon) 2000:13:15-25.

5. Kuhn TS. The structure of scientific revolutions. 2nd edn. Chicago: University of Chicago Press, 1970.

6. Nowotny H, Scott P, Gibbons M. Rethinking science. Knowledge and the public in an age of uncertainty. Oxford: Blackwell Publishers, 2001.

7. Funtowicz SO, Ravetz JR. Science for the post-normal age. Futures 1993;25:739-55

8. Haraway D. Situated knowledges: the science question in feminism and the privilege of partial perspective. In: Haraway D, ed. Simians, cyborgs, and women. The reinvention of nature. New York: Routledge, 1991:182-201.

9. Kenen RH. The at-risk status and technology: a diagnostic invitation and the 'gift' of knowing. Soc Sci Med 1996;42:145-53.

10. Sibbald B, Bojke C, Gravelle H. National survey of job satisfaction and retirement intentions among general practitioners in England. BMJ 2003;326:22-4.

11. Freeman AC, Sweeny K. Why general practitioners do not implement evidence: a qualitative study. BMJ 2001;323:1100-2.

12. Gubb JD. Commentary: unintended consequences: what of quality outside the QOF? Br J Gen Pract 2009;59:e173-4.

13. Fisher ES, Welch HG. Avoiding the unintended consequences of growth in medical care: how might more be worse? JAMA 1999;281:446-53.

14. Reventlow SD, Hvas L, Malterud K. Making the invisible body visible. Bone scans osteoporosis and women's bodily experiences. Soc Sci Med 2006;62:2720-31.

15. Hofmann B. On the value-ladenness of technology in medicine. Med Health Care Philos 2001;4:335-46. 
16. Hetlevik I. Evidence-based medicine in general practice: a hindrance to optimal medical care? Scand J Prim Health Care 2004;22:136-40.

17. Kirkengen AL, Ulvestad E. [Heavy burdens and complex disease - an integrated perspective] (In Norwegian). Tidsskr Nor Laegeforen 2007;127:3228-31. http:// www.tidsskriftet.no/index.php?seks_id_eng=14150\&seks_id=1628567 (Accessed 22 Apr 2010).

18. Moynihan R, Smith R. Too much medicine? Almost certainly. BMJ 2002;324:859-60.

19. Gervás J, Starfield B, Heath I. Is clinical prevention better than cure? Lancet 2008;372:1997-9.

20. Malterud K. The legitimacy of clinical knowledge: towards a medical epidemiology embracing the art of medicine. Theor Med 1995;16:183-98.

21. McWhinney IR. Primary care: core values. Core values in a changing world. BMJ 1998;316:1807-9.
22. Patsopoulus NA, Analatos A loannidis JP. Origin and funding of the most frequently cited papers in medicine: database analysis. BMJ 2006;332:1061-4.

23. Agnell M. Industry-sponsored clinical research. a broken system. JAMA 2008;300:1069-71.

24. Patel V. Cultural factors and international epidemiology. Br Med Bull 2001:57:33-45.

25. Foucault M, Gordon C. Power/knowledge: selected interviews and other writings 1972-77. Brighton: Harvester Press, 1980.

26. Dean K. The role of methods in maintaining orthodox beliefs in health research Soc Sci Med 2004;58:675-85

27. Royal Society, Royal Academy of Engineering. Nanosciences and Nanotechnologies: opportunities and uncertainties, 2004: http://www.nanotec.org. uk/finalReport.htm (Accessed 22 Jan 2010).

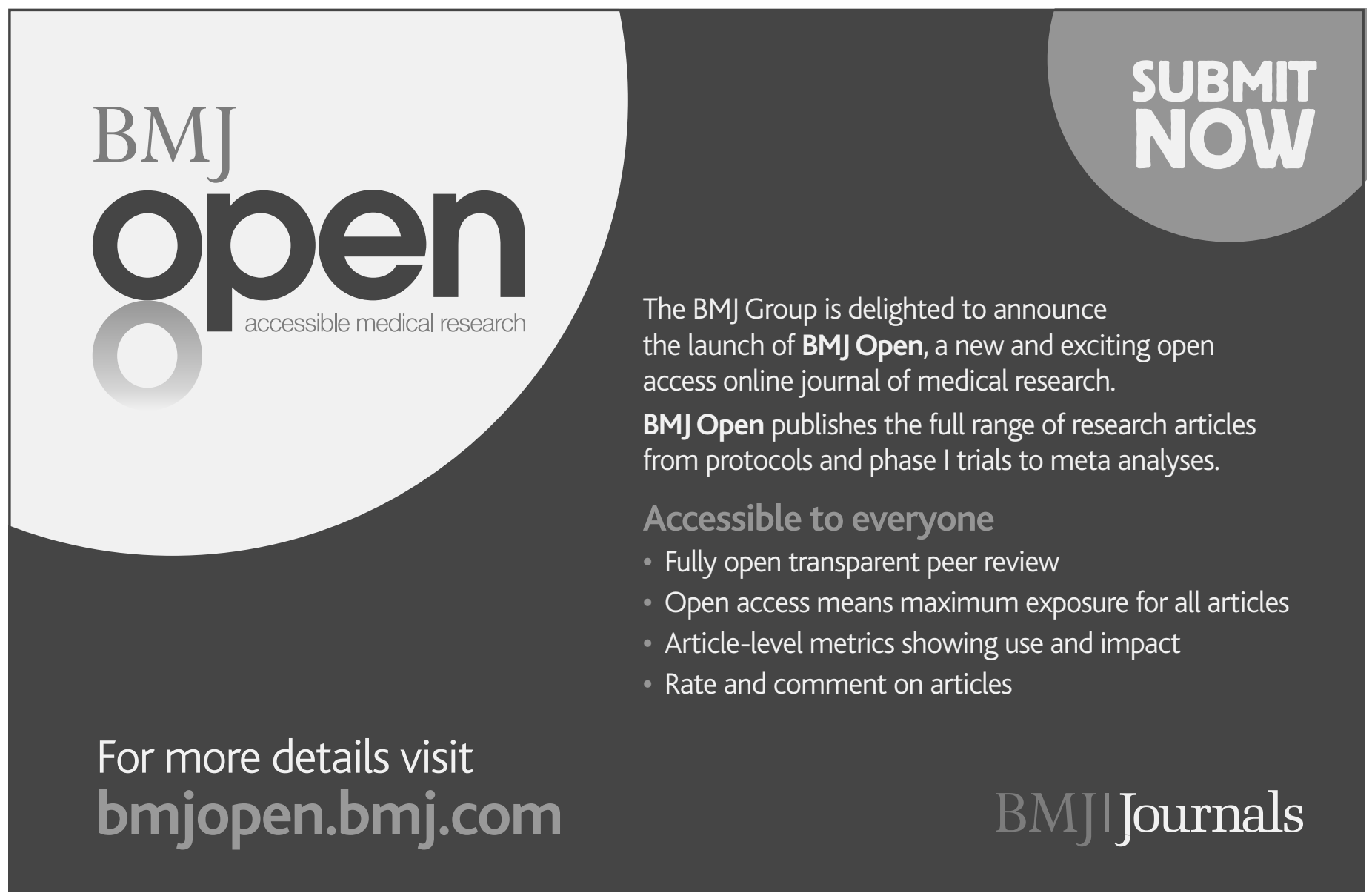

